TAVARES, AEB; CLAUDIO, MTR; NAKADA-FREITAS, PG; CARDOSO, AII. 2016. Densidade de plantio na produção de ervilha-de-vagem. Horticultura Brasileira 34: 289-293. DOI - http://dx.doi.org/10.1590/S0102-053620160000200021

\title{
Densidade de plantio na produção de ervilha-de-vagem
}

\author{
Ana EB Tavares ${ }^{1}$; Marina TR Claudio ${ }^{2}$; Pâmela G Nakada-Freitas ${ }^{3}$; Antonio II Cardoso ${ }^{1}$ \\ ${ }^{1}$ Universidade Estadual Paulista (UNESP), Botucatu-SP, Brasil; anaemiliatavares@yahoo.com.br, ismaeldh@fca.unesp.br; ${ }^{2}$ Sakata Seed \\ Sudamerica, Bragança Paulista-SP, Brasil; marinatre@hotmail.com; ${ }^{3}$ Universidade Estadual Paulista (UNESP), Dracena-SP, Brasil; \\ pamelanakada@dracena.unesp.br
}

\section{RESUMO}

A otimização do espaço na produção de hortaliças é de suma importância para o agricultor; algumas vezes esse é o limiar do lucro. Novos arranjos de plantas com disposições diferentes buscam maximizar a produção. Objetivou-se com este trabalho avaliar a produtividade de ervilha de vagens comestíveis em diferentes densidades de plantio, variando o espaçamento entre covas e o número de plantas por cova. O delineamento experimental utilizado foi de blocos ao acaso, com oito tratamentos no esquema fatorial $4 \times 2$ (espaçamentos entre covas de 0,$2 ; 0,3 ; 0,4$ e $0,5 \mathrm{~m}$ com 1 ou 2 plantas por cova), representando densidades de 20.000 a 100.000 plantas/ha para o espaçamento de 1,0 m entre linhas, com seis repetições. Foram avaliadas a produtividade total e comercial, a produção de vagens comerciais por planta e o número de vagens comerciais. Os dados foram submetidos ao teste $\mathrm{F}$, sendo as médias referentes ao número de plantas por cova comparadas pelo teste de Tukey e as referentes aos espaçamentos pela análise de regressão. Foi obtida maior produtividade de vagens comerciais (15,53 t/ha com 2 plantas por cova) e menor produção por planta ( $150 \mathrm{~g}$ com 2 plantas por cova), quanto menor o espaçamento $(0,2 \mathrm{~m})$. Caso o produtor resolva plantar com um espaçamento maior, aconselha-se o uso de duas plantas por cova.

Palavras-chave: Pisum sativum, produtividade, espaçamento.
ABSTRACT

\section{Plant density in the production of edible pod pea}

The optimization of space in vegetable production is very important to the farmer; sometimes this is the threshold of profit. New arrangements of plants with different provisions seek to maximize production. The objective of this research was to evaluate the productivity of edible pea pods in different planting densities, varying the spacing between holes and the number of plants per hole. The experimental design was randomized blocks, with eight treatments in a factorial scheme $4 \times 2$ (spacing among holes of $0.2,0.3,0.4$ and $0.5 \mathrm{~m}$ with 1 or 2 plants per hole), representing densities of 20,000 to 100,000 plants/ha for spacing of $1.0 \mathrm{~m}$ between rows, with six replications. We evaluated the total production/ha, the marketable production/ha and per plant, and the number of marketable pods/ha and per plant. The data were submitted to the F test, and the means concerning number of plants per hole were compared by Tukey's test and the spacing between holes by regression analysis. Higher productivity was obtained (15.53 t/ha with 2 plants per hole) and lower production of pods per plant ( $150 \mathrm{~g}$, with 2 plants per hole), the smaller the spacing $(0.2 \mathrm{~m})$. However, if the farmer decides to plant on greater spacing, the density of two plants per hole is recommended.

Keywords: Pisum sativum, yield, spacing.

(Recebido para publicação em 12 de fevereiro de 2015; aceito em 7 de dezembro de 2015) (Received on February 12, 2015; accepted on December 7, 2015)

\begin{abstract}
A ervilha (Pisum sativum) pertencente à família Fabaceae adapta-se melhor a regiões de temperatura amena ou a regiões tropicais com altitudes elevadas (Gritton, 1980).

É uma hortaliça de alto valor nutritivo (Filgueira, 2008) com amplas alternativas de uso na alimentação. Pode ser classificada como ervilhas para reidratação, com cultivares que produzem grãos lisos e verdes, colhidos secos e posteriormente reidratados pelas agroindústrias; ervilhas para grãos colhidos ainda verdes, macios e rapidamente enlatados; ervilhas-de-vagem comestível que apresentam baixos teores de fibras e podem ser consumidas na forma de vagens verdes, incluindo grãos imaturos; e ervilhas para grãos, que produzem
\end{abstract}

grãos verdes e graúdos. As cultivares de vagens comestíveis apresentam flores roxas ou brancas e são de crescimento indeterminado. A CEAGESP-SP registrou a comercialização de 2299 toneladas em 2011 e 995 toneladas de janeiro a julho de 2012 (Agrianual, 2013).

A fim de obter maior produtividade, principalmente em hortaliças pouco estudadas, é necessário pesquisar diferentes tratos culturais, inclusive a organização estrutural das plantas, que podem ser manipuladas através de alterações na densidade de plantio. Em princípio, o melhor arranjo é aquele que propicia melhor utilização de água, luz e nutrientes, através de uma distribuição uniforme de plantas na área (Bezerra et al., 2014). A redução da área fotossinté- tica pode comprometer a produtividade no estádio reprodutivo (Sá et al., 2004).

Existem poucos trabalhos em que se estudou a densidade de plantio da ervilha, sendo a maioria com cultivares para produção de grãos (Islam et al., 2002; Torales et al., 2011; Zárate et al., 2012). No cultivo de ervilha-de-vagem comestível, o espaçamento utilizado no Brasil varia de 0,8 a 1,0 m entre linhas e 0,4 a $0,5 \mathrm{~m}$ entre plantas (Filgueira, 2008).

Alguns olericultores produzem ervilha-de-vagem como alternativa de rotação de cultura, utilizando a estrutura de condução do tomateiro. Entretanto, essa alternativa apresenta dificuldade em diminuir o espaçamento e aumentar a produção por área. Uma alternativa 
viável seria utilizar duas plantas por cova, maximizando o aproveitamento da área plantada e utilizando a estrutura já instalada do tomateiro. Objetivou-se com este trabalho avaliar a produtividade de ervilha-de-vagem em diferentes densidades de plantio, variando o espaçamento entre covas e o número de plantas por cova.

\section{MATERIAL E MÉTODOS}

O trabalho foi desenvolvido de maio a agosto de 2011 na Fazenda Experimental São Manuel, localizada no município de São Manuel-SP, pertencente à Faculdade de Ciências Agronômicas da Universidade Estadual Paulista em Bo-

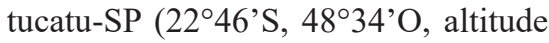
de $740 \mathrm{~m}$ ). O clima da região, conforme os critérios adotados por Köppen, baseado nas observações meteorológicas, é Cfa (clima temperado quente úmido) (Cunha \& Martins, 2009).

O solo utilizado no experimento é um Latossolo Vermelho Distrófico Típico, com os seguintes resultados obtidos na análise química: $\mathrm{pH}_{\left(\mathrm{CaCl}_{2}\right)}=$ 6,$3 ; \mathrm{P}_{\text {resina }}=42 \mathrm{mg} / \mathrm{dm}^{3} ;$ M.O. $=20 \mathrm{~g} / \mathrm{dm}^{3}$; $\mathrm{V}=70 \%$; e os valores de $\mathrm{H}+\mathrm{Al} ; \mathrm{K}$; $\mathrm{Ca}$; $\mathrm{Mg}$; SB e CTC, expressos em mmol/ $\mathrm{dm}^{3}$, respectivamente de: $14 ; 10 ; 50 ; 10$; 60 e 95 . Com base na análise química do solo, não foi necessária a calagem. Portanto, foi realizada somente a adubação de plantio, conforme recomendação sugerida por Raij et al. (1997). As adubações em cobertura foram realizadas quinzenalmente com uréia e cloreto de potássio. Foi utilizada a mesma quantidade de adubo por cova, independente da densidade.

Foram estudados oito tratamentos, no esquema fatorial $4 \times 2$ (espaçamento entre covas de 0,$2 ; 0,3 ; 0,4$ e $0,5 \mathrm{~m}$ com uma ou duas plantas por cova), no delineamento experimental em blocos casualizados, com seis repetições e seis covas por parcela, sendo quatro úteis. $\mathrm{O}$ espaçamento entre linhas foi constante em todas as densidades $(1,0 \mathrm{~m})$. As densidades de plantio variaram de 20.000 a 100.000 plantas/ha.

Foi utilizada a cultivar MK13 da Sakata ${ }^{\circledR}$ Seed Sudamerica Ltda, caracterizada por ser de crescimento indetermi- nado, com alta produtividade, qualidade de vagem e alto nível de resistência ao oídio (Erysiphe sp.) (Sakata, 2011). A semeadura foi feita em bandejas de poliestireno expandido de 128 células, contendo substrato comercial, com uma semente por célula. Quando emitiram a segunda folha definitiva, as mudas foram transplantadas. O tutoramento foi feito de forma vertical e individualizado por planta, de modo a evitar o seu tombamento e respeitando o espaçamento proposto entre covas.

As colheitas foram realizadas a cada dois dias, quando os grãos apresentavam-se salientes, sem deformar as vagens. O inicio foi aos 65 dias após o transplante das mudas e finalizou-se aos 121 dias. Foram avaliadas as variáveis produtividade total e comercial ( $\mathrm{t} / \mathrm{ha}$ ), produção de vagens comerciais por planta $(\mathrm{kg})$ e número de vagens comerciais por hectare e por planta. Foram classificadas como não comerciais as vagens que apresentaram coloração amarela, tortas ou fibrosas. Os dados foram submetidos à análise de variância, com aplicação de teste de Tukey para comparação do número de plantas por cova e análise de regressão para comparação entre espaçamentos. A análise estatística foi realizada através do programa SISVAR 5.3 (Ferreira, 2010).

\section{RESULTADOS E DISCUSSÃO}

Observou-se aumento linear na produção de vagens comerciais por planta, quanto maior o espaçamento entre covas. Para cada $0,1 \mathrm{~m}$ de acréscimo no espaçamento obteve-se aumento de $43 \mathrm{~g} /$ planta nos tratamentos conduzidos tanto com uma ou duas plantas por cova (Figura 1). Para os tratamentos com duas plantas por cova o aumento correspondeu a $86 \mathrm{~g} /$ cova. Cardoso \& Ribeiro (2006) em feijão-caupi, Andreoli \& Fontes (1980) e Zárate et al. (2012), com ervilha de grãos, obtiveram resultado semelhante quando testaram diferentes densidades de plantio, com um decréscimo linear na produção e número de vagens por planta, em decorrência do aumento da densidade de plantio.

Os tratamentos com uma planta por cova apresentaram produção de vagens comerciais por planta maior que os tratamentos com duas plantas por cova, com exceção do espaçamento de 0,4 m, onde não houve diferença estatística (Tabela 1). A explicação pode estar relacionada com o aumento do sombreamento entre plantas e com isso diminuição do índice fotossintético. A produção por planta é diretamente proporcional à fotossíntese realizada pela mesma, até que a planta atinja um ponto máximo de produção (Andriolo, 1999). Também há maior competição entre plantas quanto maior a densidade, principalmente por água e nutrientes (Azpilicueta et al., 2012), já que a adubação foi igual para todos os tratamentos.

Essa correlação entre produção por planta e densidade também foi constatada em outras hortaliças (Caldas et al., 2008; Pôrto et al., 2012; Corrêa et al., 2014; Takahashi \& Cardoso, 2014). Manetti (2010), estudando três densidades de plantio em ervilha $(25.000,50.000$ e 100.000 plantas/ha), também obteve maior produção por planta quanto menor a densidade.

As médias do número de vagens comerciais por planta se ajustaram ao modelo de regressão linear, com aumento de 4,51 e 3,95 no número de vagens a cada aumento de $0,1 \mathrm{~m}$ no espaçamento entre covas para os tratamentos com uma e duas plantas por cova, respectivamente (Figura 1). Independentemente do espaçamento entre covas, a produção de vagens foi maior com uma planta por cova (média de 31,4 vagens por planta) em comparação a duas plantas por cova (média de 20,6 vagens por planta). Gassi et al. (2009), em ervilha; Hartmann-Schmidt et al. (2010), em feijão-vagem, e Cardoso \& Ribeiro (2006), em feijão-caupi, afirmaram que o número de vagens por planta é o primeiro componente de produção a ser definido na fase reprodutiva, sendo mais facilmente afetado pelo aumento da população, devido ao ambiente de competição por radiação, água e nutrientes.

Apesar da diminuição do número de vagens por planta nos tratamentos com duas plantas por cova foi obtida maior produtividade no número de vagens comerciais por hectare, pois o maior número de plantas por cova compensa a menor produção por planta. Apenas 
Tabela 1. Produção comercial por planta, número de vagens por ha, produtividade total e comercial de ervilha-de-vagem em função do número de plantas por cova nos diferentes espaçamentos entre covas (EEC) \{marketable production per plant, number of pods per ha, total and marketable productivity of pea pod depending on the number of plants per hole in different spacing between hole (EEC) \}. São Manuel, UNESP, 2011.

\begin{tabular}{|c|c|c|c|c|}
\hline \multirow{2}{*}{$\operatorname{EEC~(m)~}$} & \multicolumn{2}{|c|}{ Produção comercial por planta (kg) } & \multicolumn{2}{|c|}{$\mathrm{N}^{0}$ vagens/ha $(\mathrm{x} 1.000)$} \\
\hline & 1 planta/cova & 2 plantas/cova & 1 planta/cova & 2 plantas/cova \\
\hline 0,2 & $0,25 \mathrm{~A}$ & $0,15 \mathrm{~B}$ & $1212,50 \mathrm{~B}$ & $1484,37 \mathrm{~A}$ \\
\hline 0,3 & $0,31 \mathrm{~A}$ & $0,19 \mathrm{~B}$ & $1002,77 \mathrm{~A}$ & $1156,25 \mathrm{~A}$ \\
\hline 0,4 & $0,32 \mathrm{~A}$ & $0,26 \mathrm{~A}$ & $820,31 \mathrm{~B}$ & $1223,96 \mathrm{~A}$ \\
\hline 0,5 & $0,40 \mathrm{~A}$ & $0,28 \mathrm{~B}$ & $767,08 \mathrm{~B}$ & $1025,00 \mathrm{~A}$ \\
\hline \multirow[t]{2}{*}{$\mathrm{CV}(\%)$} & \multicolumn{2}{|c|}{29,49} & \multicolumn{2}{|c|}{19,64} \\
\hline & \multicolumn{2}{|c|}{ Produtividade total (t/ha) } & \multicolumn{2}{|c|}{ Produtividade comercial (t/ha) } \\
\hline 0,2 & $16,92 \mathrm{~B}$ & $20,58 \mathrm{~A}$ & $12,42 \mathrm{~A}$ & $15,53 \mathrm{~A}$ \\
\hline 0,3 & $14,90 \mathrm{~A}$ & $17,50 \mathrm{~A}$ & $10,42 \mathrm{~A}$ & $12,64 \mathrm{~A}$ \\
\hline 0,4 & $10,92 \mathrm{~B}$ & $17,86 \mathrm{~A}$ & $8,14 \mathrm{~B}$ & $12,95 \mathrm{~A}$ \\
\hline 0,5 & $10,82 \mathrm{~B}$ & $14,70 \mathrm{~A}$ & $7,96 \mathrm{~A}$ & $11,12 \mathrm{~A}$ \\
\hline CV (\%) & \multicolumn{2}{|c|}{19,23} & \multicolumn{2}{|c|}{24,18} \\
\hline
\end{tabular}

Médias seguidas da mesma letra na linha não diferem pelo teste de Tukey $(p>0,05)$ (means followed by the same letter in the line do not differ by Tukey test, $\mathrm{p}>0.05$ ).

para o espaçamento $0,3 \mathrm{~m}$ o número de vagens por hectare não diferiu significativamente para o fator número de plantas por cova (Tabela 1).

Os tratamentos com duas plantas por cova apresentaram maior média de produtividade total, fato que pode ser justificado pelo aumento da densidade de plantio e com isso maior produtividade. Somente o tratamento com 0,3 $m$ de espaçamento entre covas não apresentou diferença significativa para as médias com uma e duas plantas por cova (Tabela 1).

Com a diminuição do espaçamento, a produtividade total de ervilha aumentou de forma linear. Para cada diminuição de $0,1 \mathrm{~m}$ no espaçamento entre covas houve um aumento na produtividade de 2,23 $\mathrm{t} / \mathrm{ha}$ nos tratamentos com uma planta por cova e $1,73 \mathrm{t} / \mathrm{ha}$ nos tratamentos com duas plantas por cova (Figura 1).

Outros trabalhos com ervilha revelam resultados semelhantes, com aumento da produtividade quanto maior a densidade de plantio (Kahn \& Nelson, 1991; Islam et al., 2002; Manetti, 2010; Torales et al., 2011), mostrando que a espécie tolera o adensamento, pelo menos nas densidades estudadas.

Para a característica produtividade comercial (t/ha), apenas no espaçamento entre covas de $0,4 \mathrm{~m}$ foi observada superioridade estatística com duas plantas por cova (Tabela 1), apesar de que em todos os espaçamentos com duas plantas por cova os valores terem sido numericamente maiores.

Observou-se que, quanto menor o espaçamento entre covas, maior a produtividade comercial, com aumento de 1,57 e 1,29 t/ha para cada redução de $0,1 \mathrm{~m}$ no espaçamento nos tratamentos com uma e duas plantas por cova, respectivamente (Figura 1). Segundo Filgueira (2008), a produtividade de ervilha é de 2 a 3 t/ha de vagens. Os valores obtidos (Figura 1 e Tabela 1), 7,9 a $15,5 \mathrm{t} / \mathrm{ha}$ de vagens comerciais, foram muito superiores, provavelmente pelas condições ambientais favoráveis, $\mathrm{o}$ tempo de colheita e a cultivar utilizada. Verificou-se que a temperatura média foi de $22^{\circ} \mathrm{C}$, estando dentro da faixa favorável ao cultivo da ervilha-de-vagem que, segundo Filgueira (2008), não deve ultrapassar $27^{\circ} \mathrm{C}$, além da quase completa ausência de chuvas (menos de 20 $\mathrm{mm}$ ao longo do ciclo) e utilização de irrigação controlada. Quanto à colheita, iniciou-se aos 65 dias após a semeadura e estendeu-se por 56 dias, quando, segundo Filgueira (2008), o período de colheita é de 15 dias ou pouco mais. Ressalta-se, que neste experimento foi utilizada uma cultivar resistente a oídio e a época de plantio, com pouca chuva e umidade baixa, contribuiu para manter o plantio livre de patógenos, mesmo nos maiores adensamentos.

A otimização do espaço na produção de hortaliças é de suma importância para o agricultor, além disso, algumas vezes esse é o limiar do lucro. Novos arranjos de plantas com disposições diferentes buscam maximizar a produção. Neste experimento, com o aumento da densidade de plantio, houve uma diminuição da produção por planta e aumento na produtividade. Embora a condução das plantas se torne mais difícil e acarrete aumento no custo de produção, com maior necessidade de estrutura e mão-de-obra, os ganhos na produtividade com a redução no espaçamento são significativos.

Caso o produtor utilize uma estrutura de tutoramento pré-estabelecida de 0,4 ou $0,5 \mathrm{~m}$, utilizada por exemplo no cultivo do tomate, os resultados mostram que se pode utilizar duas plantas por cova como alternativa para aumentar a densidade sem alterar o espaçamento e, consequentemente, aumentar a produtividade.

A produção de vagens por planta é maior com uma planta por cova, e a redução no espaçamento entre covas 


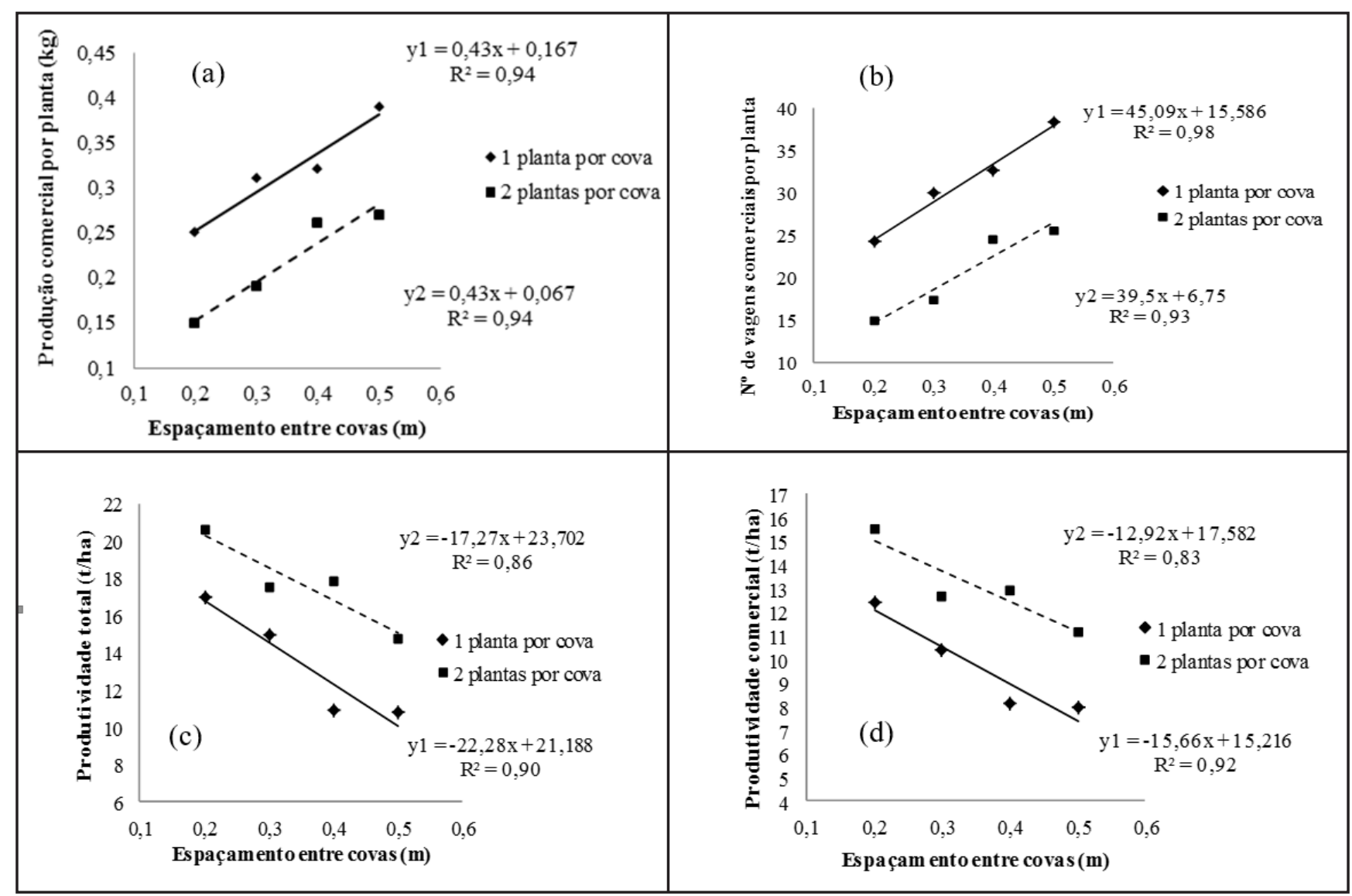

Figura 1: Produção comercial por planta (a), número de vagens comerciais por planta (b), produtividade total (c), produtividade comercial (d) em função do espaçamento entre covas com uma ou duas plantas por cova \{marketable production per plant (a), number of marketable pods per plant (b), total productivity (c), marketable productivity (d) depending on the spacing between holes with one or two plants per hole\}. São Manuel, UNESP, 2011.

promove maior produtividade.

\section{REFERÊNCIAS}

AGRIANUAL. Anuário da Agricultura Brasileira . 2013. São Paulo: FNP. 80p.

ANDREOLI, C; FONTES, RR. 1980. Influência do espaçamento e da população de plantas na produtividade de sementes de ervilha no Distrito Federal. Revista Brasileira de Sementes 2: 89-96.

ANDRIOLO, JL. 1999. Fisiologia das culturas protegidas. Santa Maria: UFSM. 142p.

AZPILICUETA, M; IRIGOYEN, I; LASA, B; MURO, J; APARICIO-TEJO, PM. 2012. Yield and quality of sugar snap pea in the Ebro Valley: sowing date and seed density. Scientia Agricola 69: 320-326.

BEZERRA, FTC; DUTRA, AS; BEZERRA, MAF; OLIVEIRA FILHO, AF; BARROS, GL. 2014. Comportamento vegetativo e produtividade de girassol em função do arranjo espacial das plantas. Revista Ciência Agronômica 45: 335-343.

CALDAS, RR; SENO, S; SELEGUINI, A; FERNANDES, FM; JUNIOR, MJAF. 2008.
Característica de recipiente e densidade de plantas de pepino, cultivadas em substrato de fibra de coco com fertirrigação. Horticultura Brasileira 26: s4881-s4885.

CARDOSO, MJ; RIBEIRO, VQ. 2006. Desempenho agronômico do feijão-caupi, cv. Rouxinol, em função de espaçamentos entre linhas e densidades de plantas sob regime de sequeiro. Revista Ciência Agronômica 37: 102-105.

CORREAA, CV; CARDOSO, AII; SOUZA, LG; ANTUNES, WLP; MAGOLBO, LA. 2014. Produção de beterraba em função do espaçamento. Horticultura Brasileira 32: 140-144.

CUNHA, AR; MARTINS, D. 2009. Classificação climática para os municípios de Botucatu e São Manuel, SP. Irriga 14: 1-11.

FERREIRA, DF. 2010. Sisvar - Sistema de análise de variância. Versão 5.3. Lavras-MG: UFLA.

FILGUEIRA, FAR. 2008. Novo manual de olericultura: agrotecnologia moderna na produção e comercialização de hortaliças. Viçosa: UFV. 421p.

GASSI, RP; ZÁRATE, NAH; VIEIRA, MC; GOMES, HE; MUNARIN, EEO; RECH, J. 2009. Espaçamentos entre plantas e número de fileiras no canteiro na produção da ervilha.
Horticultura Brasileira 27: 549-552.

GRITTON, ET. 1980. Field pea. In: FEHR, WR; HADLEY, HH (eds.). Hybrdization of crop plants. Madison: American Society of Agronomy. p.347-356.

HARTMANN-SCHMIDT, MA; ECHER, MM; GUIMARÃES, VF; MEINERZ, CC; HACHMANN, TL; BARILLI, DR. 2010. Desempenho de duas cultivares de feijãovagem em diferentes densidades sob cultivo protegido. Horticultura Brasileira 28: 240245.

ISLAM, MS; RAHMAN, MA; SALAM, MA; MASUM, ASMH; RAHMAN, MH. 2002. Growth and vegetable pod yield of edible podded pea as influenced by sowing time and plant density. Journal of Biological Sciences 2: 706-709.

KAHN, BA; NELSON, WA. 1991. Row arrangement can affect yield and pod distribution pattern of trellised snow peas. HortScience 26: 532-534.

MANETTI, FA. 2010. Produtividade de linhagens unifloras e bifloras de ervilha (Pisum sativum L.) de vagens comestiveis em função da densidade de plantio. Botucatu: UNESP-FCA. 27p. (Tese doutorado).

PÔRTO, DRQ; CECÍlIO FILHO, AB; 
REZENDE, BLA; BARROS JÚNIOR, AP; SILVA, GS. 2012. Densidade populacional e época de plantio no crescimento e produtividade de couve-flor cv. Verona 284. Caatinga 25: 92-98.

RAIJ, B; CANTARELLA, H; QUAGGIO, JA; FURLANI, AMC. 1997. Recomendações de adubação e calagem para o Estado de São Paulo. Campinas: Instituto Agronômico. $285 \mathrm{p}$.

SÁ, JS; CRUCIANI, DE; MINAMI, K. 2004.
Efeitos de inundações temporárias do solo em plantas de ervilha. Horticultura Brasileira 22: 50-54.

SAKATA - Sakata Seed Sudamerica. 2011. Disponível em http://www.sakata.com.br Acessado em 20 de junho de 2011.

TAKAHASHI, K; CARDOSO, AII. 2014. Plant density in production of mini lettuce cultivars in organic system management. Horticultura Brasileira 33: 342-347.

TORALES, EP; ZÁRATE, NAH; VIEIRA,
MC; GASSI, RP; ROCHA, SF; TABALDI, LA. 2011. Fileiras de plantas no canteiro e número de sementes por cova na produção agroeconômica de ervilha "Luciana 50". In: CONGRESSO BRASILEIRO DE OLERICULTURA, 51. Anais... Viçosa: ABH. p.1807-1814.

ZARATE, NAH; GASSI, RP; VIEIRA, MC; TABALDI, LA; TORALES, EP; FACCIN, FC. 2012. Espaçamentos entre plantas e cobertura do solo com cama-de-frango na produção de ervilhas. Bragantia 71: 42-46. 